\title{
Erratum to: The Social Bond
}

\section{Erratum to: \\ E.W. Aslaksen, The Social Bond, https://doi.org/10.1007/978-3-319-68741-4}

In the original version of the book, open access details were provided which have now been removed as this is not an open access book. The book has been updated with the changes.

The updated online version of this book can be found at https://doi.org/10.1007/978-3-319-68741-4 